\title{
KUALITAS TANAH PADA LAHAN SAWAH DENGAN IRIGASI AIR RAWA JOMBOR DI KECAMATAN BAYAT KABUPATEN KLATEN
}

\section{SOIL QUALITIY IN PADDY FIELDS WITH IRRIGATION WATER FROM RAWA JOMBOR IN BAYAT DISTRICT, KLATEN REGENCY}

\author{
Putri Puji Astuti'), Didi Saidi' ${ }^{2 *)}$, AZ. Purwono Budi Santosa ${ }^{2)}$ \\ ${ }^{1)}$ Prodi Agroteknologi, Universitas Pembangunan Nasional Veteran Yogyakarta \\ ${ }^{2)}$ Prodi Ilmu Tanah, Universitas Pembangunan Nasional Veteran Yogyakarta \\ ${ }^{*}$ Corresponding author E - mail: didi.saidi@upnyk.ac.id
}

\begin{abstract}
Most of the paddy field irrigation water in Bayat District, Klaten Regency have supplied by Rawa Jombor. The organic waste in the water of Rawa Jombor has caused nutrient enrichment in water, it has increased soil nutrients through irrigation. However, if the nutrient levels have exceeded the irrigation water threshold certainly has affected the soil quality. This research was conducted to determine the quality of Rawa Jombor's irrigation water and determine the soil quality index on paddy fields. The method used in this study was a survey method. Soil sampling was determined based on the Land Map Unit was made from overlay of land use maps (paddy fields) and soil type with details of LMU 1 (technical irrigation paddy fields with Litosol soil types), LMU 2 (technical irrigation paddy fields with Alluvial soil types), LMU 3 (technical irrigation paddy fields with Regosol soil types), and LMU 0 (rain field paddy with Regosol soil types). Water sample was taken based on the irrigation water inlet every LMU. The results showed that the irrigation water quality still met with the water quality criteria for irrigation. Soil quality was determined by the Soil Quality Index which was calculated based on the criteria of Mausbach and Seybold (1998). The results of the soil quality index LMU 1 (0.55) with moderate criteria, LMU 2 (0.48) with moderate criteria, LMU $3(0.59)$ with moderate criteria, and LMU 0 (0.71) with good criteria.
\end{abstract}

\section{Keywords: Soil Quality, Paddy fields, Water Quality, Rawa Jombor}

\begin{abstract}
ABSTRAK
Sebagian besar air irigasi persawahan di Kecamatan Bayat, Kabupaten Klaten disuplai oleh Rawa Jombor. Sampah organik di perairan Rawa Jombor menyebabkan pengayaan unsur hara pada air, meningkatkan unsur hara tanah melalui irigasi. Namun jika kadar unsur hara telah melebihi ambang batas air irigasi tentu berpengaruh terhadap kualitas tanah. Penelitian ini dilakukan untuk mengetahui kualitas air irigasi Rawa Jombor dan mengetahui indeks kualitas tanah pada lahan sawah. Metode yang digunakan dalam penelitian ini adalah metode survei. Pengambilan sampel tanah ditentukan berdasarkan Peta Satuan yang dibuat dari overlay peta penggunaan lahan (sawah) dan jenis tanah dengan rincian SPL 1 (sawah irigasi teknis dengan jenis tanah Litosol), SPL 2 (sawah irigasi teknis dengan Aluvial jenis tanah), SPL 3 (sawah irigasi teknis dengan jenis tanah Regosol), dan SPL 0 (padi sawah dengan jenis tanah Regosol). Pengambilan sampel air dilakukan berdasarkan inlet air irigasi setiap SPL. Hasil penelitian menunjukkan bahwa kualitas air irigasi masih memenuhi kriteria kualitas air untuk irigasi.
\end{abstract}


Kualitas tanah ditentukan dengan Indeks Kualitas Tanah yang dihitung berdasarkan kriteria Mausbach dan Seybold (1998). Hasil indeks kualitas tanah SPL $1(0,55)$ dengan kriteria sedang, SPL $2(0,48)$ dengan kriteria sedang, SPL $3(0,59)$ dengan kriteria sedang, dan SPL $0(0,71)$ dengan kriteria baik.

\section{Kata Kunci: Kualitas Tanah, Sawah, Kualitas Air, Rawa Jombor}

\section{PENDAHULUAN}

Menurut Plaster (2003) dalam Christine (2009), kualitas tanah merupakan kapasitas dari suatu tanah dalam suatu lahan untuk menyediakan fungsi-fungsi yang dibutuhkan manusia atau ekosistem alami dalam waktu yang lama. Fungsi tersebut merupakan kemampuannya untuk mempertahankan pertumbuhan dan produktivitas tumbuhan serta hewan, mempertahankan kualitas udara dan air atau mempertahankan kualitas lingkungan. Menurunnya fungsi tanah dapat menyebabkan terganggunya ekosistem di sekitarnya.

Sebagian dari lahan sawah di Kecamatan Bayat merupakan lahan sawah dengan irigasi teknis. Lokasi penelitian yaitu Desa Jotangan, Desa Kebon, Desa Talang, Desa Tawangrejo, dan Desa Gununggajah merupakan beberapa sawah dengan irigasi teknis di Kecamatan Bayat. Lahan sawah irigasi tersebut mendapatkan pasokan air irigasi yang berasal dari Rawa Jombor. Kebutuhan air untuk irigasi pertanian harus memenuhi dari segi kuantitas dan kualitasnya. Rawa Jombor memiliki kualitas air yang rendah, beberapa parameter telah melebihi ambang baku mutu apabila digunakan sebagai air irigasi. Penelitian Ferril (2014), menunjukkan kandungan fosfat terendah yaitu 0,50 $\mathrm{mg} / \mathrm{l}$ pada perairan bebas, dan tertinggi yaitu $10,80 \mathrm{mg} / \mathrm{l}$ pada warung apung. Menurut PP No. 82 tahun 2001 tentang Pengelolaan Kualitas Air dan Pengendalian Pencemaran Air, bahwa ambang batas maksimal fosfat untuk irigasi adalah $5 \mathrm{mg} / \mathrm{L}$. Berdasarkan penelitian Kusumaningtyas (2015), rata-rata DO 0,98 mg/L berada di bawah baku mutu yang ditentukan. Nilai BOD 5,23 mg/L dan COD 52,1 $\mathrm{mg} / \mathrm{L}$ pada stasiun inlet,tengah, dan outlet perairan Rawa Jombor telah melebihi ambang baku mutu yang ditentukan untuk perairan.

Rawa Jombor memiliki kualitas air yang rendah karena memiliki tiga DAS sebagai saluran masuk air yaitu DAS Kali Danguran Bajing, DAS Kali Gebyok, dan DAS Kali Jayan yang melewati daerah permukiman dan pertanian, serta pemanfaatan Rawa Jombor secara in-situ sebagai budidaya keramba jaring ikan dan rumah makan warung apung juga menyumbangkan limbah organik di perairan Rawa Jombor. Limbah organik selanjutnya mengalami proses dekomposisi dan meningkatkan konsentrasi unsur nitrogen $(\mathrm{N})$ dan fosfor $(\mathrm{P})$.

Keberadaan unsur nitrogen dan fosfor dapat menyumbangkan hara tanah melalui air irigasi. Namun kondisi nitrogen dan fosfor yang berlebih akan menimbulkan eutrofikasi dan merangsang pertumbuhan ganggang yang tidak terkendali yang dapat memproduksi toksin. Pada air irigasi nantinya akan mempengaruhi aktivitas mikroorganisme dalam tanah sehingga akan berpengaruh pada kualitas tanah. Penelitian mengenai kualitas air di perairan Rawa Jombor telah banyak dilakukan. Namun belum ada penelitian mengenai kualitas air Rawa Jombor jika digunakan sebagai air irigasi pertanian dan pengaruhnya pada tanah yang menggunakan air tesebut. Sejauhmana kualitas air Rawa Jombor mempengaruhi perubahan kualitas tanah sawah di Kecamatan Bayat, akan dikaji melalui penelitian ini. 


\section{BAHAN DAN METODE}

Penelitian ini dilaksanakan menggunakan metode survei. Lokasi penelitian terletak di Kecamatan Bayat, Kabupaten Klaten yaitu Desa Jotangan, Desa Kebon, Desa Gununggajah, Desa Tawangrejo, dan Desa Talang. Pengambilan sampel tanah dilakukan dengan acuan berdasarkan peta kerja atau peta satuan lahan yang telah dibuat. Peta kerja didapatkan dari hasil tumpang susun (overlay) dari peta penggunaan lahan (sawah) dan peta jenis tanah. Penentuan pengambilan sampel berdasarkan Satuan Peta Lahan (SPL). Terdapat 3 Satuan Peta Lahan sawah dengan irigasi teknis, setiap SPL dilakukan 3 pengambilan titik sampel tanah ditambah 1 titik sampel pada SPL 0 yang merupakan sawah tadah hujan, sehingga terdapat 10 titik sampel tanah. Pengambilan sampel tanah dilakukan dengan metode purposive sampling yaitu menentukan pengambilan sampel dengan cara menetapkan ciri-ciri khusus yang sesuai dengan tujuan penelitian.

Pengambilan sampel air dilakukan secara grab sample pada setiap titik masuk air irigasi pada setiap SPL.

1. SPL 1, sawah irigasi teknis dengan jenis tanah Litosol. Lokasi ini memiliki jarak $2,15 \mathrm{~km}$ dengan sumber air irigasi.

2. SPL 2, sawah irigasi teknis dengan jenis tanah Alluvial. Lokasi ini berjarak 3,25 km dari jarak sumber irigasi.

3. SPL 3, sawah irigasi teknis dengan jenis tanah Regosol. Lokasi ini berjarak 4,94 km dari sumber air irigasi.

4. SPL 0, sawah tadah hujan dengan jenis tanah Regosol. Lokasi ini tidak menggunakan air irigasi dari Rawa Jombor.

Analisis sampel tanah di laboratorium dilakukan untuk penetapan: N-total, dengan metode Kjeldahl; P tersedia, dengan metode Olsen; K-tersedia, morgan wolf; C-organik, dengan metode Walkley \& Black; $\mathrm{pH} \mathrm{H}_{2} \mathrm{O}$, dengan $\mathrm{pH}$ meter; tekstur, dengan metode pipet; berat volume, dengan metode ring sampler; porositas dengan perhitungan menurut rumus $\mathrm{n}=1-(\mathrm{BV} / \mathrm{BJ})$; dan analisis sampel air dengan parameter fosfat, nitrat, $\mathrm{COD}$, dan $\mathrm{pH}$.

Kualitas air didapatkan dari hasil pengujian laboratorium, kemudian dibandingkan dengan baku mutu air irigasi berdasarkan Peraturan Pemerintah nomor 82 tahun 2001 Tentang Pengelolaan Kualitas Air dan Pengendalian Pencemaran Air. Indeks kualitas tanah dihitung berdasarkan kriteria Mausbach \& Seybold (1998) yang dimodifikasi. Modifikasi dilakukan pada beberapa hal sesuai dengan kondisi lahan penelitian yaitu:

1. Fungsi tanah dan pembobotan fungsi berdasarkan kriteria Mausbach dan Seybold (1998). Pemilihan indikator dan pembobotan disesuaikan dengan pengaruh indikator tersebut menggambarkan fungsi tanah. Misalnya pada fungsi tanah melestarikan aktivitas biologi pada indikator keharaan diberi bobot lebih tinggi daripada indikator media perakaran dan kelengasan. Begitu juga pembobotan pada tolok ukur atau parameter. Misalnya parameter jeluk perakaran diberi bobot lebih tinggi dari berat volume pada, dikarenakan parameter jeluk perakaran lebih menggambarkan indikator media perakaran.

2. Indikator kemantapan agregat didekati dengan presentase debu+lempung, dengan pertimbangan pada tanah sawah dalam penelitian ini tidak terbentuk agregat karena sampel tanah diambil dalam keadaan tergenang dan berlumpur. Pengukuran kadar debu+lempung digunakan untuk menunjukkan kuantitas bahan yang dapat berperan pada fungsi pengaturan kelengasan, filtering dan buffering dan dengan 
pertimbangan bahwa pengukuran kadar debu+lempung lebih mudah dilakukan.

3. Indikator $C$ total dapat diganti dengan $C$ organik, dengan pertimbangan bahwa pengukuran $\mathrm{C}$ organik lebih mudah dilakukan.

4. Batas atas dan batas bawah beberapa indikator tanah diturunkan atau dinaikkan, disesuaikan dengan hasil pengukuran parameter di lapangan. Misalnya untuk analisis kedalaman perakaran didapatkan nilai terendah yaitu $11 \mathrm{~cm}$ maka angka tersebut ditetapkan sebagai batas bawah.

Cara perhitungan indeks adalah sebagai berikut:

1. Indeks bobot dihitung dengan mengalikan bobot fungsi tanah (bobot 1) dengan bobot indikator tanah (bobot 2 dan bobot 3). Misalnya, indeks bobot untuk jeluk perakaran diperoleh dengan mengalikan 0,40 (bobot 1) dengan 0,33 (bobot 2) dengan 0,60 (bobot 3), dan hasilnya sama dengan 0,080.

2. Skor dihitung dengan membandingkan data pengamatan dari indikator tanah dan fungsi penilaian. Skor berkisar dari 0 untuk kondisi buruk dan 1 untuk kondisi baik. Penetapan skor melalui interpolasi sesuai dengan kisaran yang ditetapkan berdasar harkat atau berdasarkan data yang diperoleh.

3. Indeks kualitas tanah dihitung dengan mengalikan indeks bobot dan skor dari indikator.

4. Selanjutnya nilai indeks kualitas tanah dikatagorikan dalam lima kelas

Tabel 1. Kriteria Penilaian Tanah Berdasarkan Indikator Kinerja

\begin{tabular}{ccc}
\hline No & Kelas Nilai IKT & Kriteria Kualitas Tanah \\
\hline 1 & $0,80-1,00$ & Sangat Baik \\
2 & $0,60-0,79$ & Baik \\
3 & $0,40-0.59$ & Sedang \\
4 & $0,20-0,39$ & Rendah \\
5 & $0,00-0,19$ & Sangat rendah \\
\hline
\end{tabular}

Sumber: Partoyo (2005)

\section{HASIL DAN PEMBAHASAN}

\section{Kualitas Air Irigasi}

Kualitas air rawa Jombor akan digunakan sebagai air irigasi pertanian akan mempengaruhi kualitas tanah, hal ini disebabkan karena keberadaan unsur nitrogen dan fosfor dapat menyumbangkan hara tanah dan akan mempengaruhi aktivitas mikroorganisme dalam tanah sehingga akan berpengaruh pada kualitas tanah. Hasil analisis kualitas air pada badan air irigasi yang dipakai dalam penelitian ini tertera dalam Tabel 2,

Sampel air pada SPL 1 hingga SPL 3 diambil pada badan air saluran irigasi Rawa Jombor yang menuju petak sawah pengambilan sampel tanah. Berdasarkan PP No.82 Tahun 2001, karakteristik air pada badan air irigasi dari SPL 1 hingg SPL 3 telah memenuhi baku mutu air kelas IV peruntukan irigasi pertanaman. Parameter Nitrat pada SPL 1 memiliki kadar paling rendah, sedangkan semakin jauh aliran air menghasilkan kadar nitrat pada SPL 3 tinggi. Hal ini dikarenakan pada saat pengambilan sampel lahan dalam keadaan setelah pemupukan urea, sehingga 
Tabel 2. Karakteristik Air pada Badan Air Irigasi

\begin{tabular}{cccccc}
\hline \multirow{2}{*}{ Parameter } & \multirow{2}{*}{$\begin{array}{c}\text { Kadar Maksimum } \\
\text { (PP no. 82 Tahun 2001) }\end{array}$} & \multicolumn{4}{c}{ Titik Sampel Air (Inlet) } \\
\cline { 3 - 6 } & 20 & SPL 1 & SPL 2 & SPL 3 & SPL 0 \\
\hline Nitrat (mg/L) & 5 & 0,18 & 0,56 & 1,49 & 1,41 \\
Fosfat $(\mathrm{mg} / \mathrm{L})$ & 100 & 0,176 & 0,117 & 0,214 & 0,088 \\
COD $(\mathrm{mg} / \mathrm{L})$ & $5-9$ & 85,3 & 41,1 & 53,0 & 41,5 \\
pH & & 6 & 6 & 6 & 6 \\
\hline
\end{tabular}

menyebabkan akumulasi dari aliran irigasi tersebut. Pengambilan sampel air dilakukan pada saat musim hujan dan sedang terjadi hujan, dimana keadaan saluran irigasi sudah bercampur dengan air hujan. Keadaan ini menyebabkan konsentrasi bahan pencemar menjadi lebih rendah daripada bulan-bulan kemarau karena volume air telah meningkat baik pada sumber Rawa Jombor maupun pada saluran irigasi menuju petak sawah.

Satuan Peta Lahan 0 merupakan lahan yang sama sekali tidak dialiri air Rawa Jombor dan tidak memiliki jaringan irigasi. Penggambilan sampel air SPL 0 pada petak lahan sawah tadah hujan, dimana waktu pengambilan sampel tanah saat terjadi hujan. Pada sampel air SPL 0 didapatkan hasil kadar fosfat dan COD yang rendah jika dibandingkan dengan kadar pada lokasi bukan SPL 0. Keadaan tersebut dikarenakan lokasi SPL 0 merupakan sawah tadah hujan yang sumber air irigasi berasal dari air hujan. Rendahnya COD menggambarkan tidak banyaknya pencemaran air oleh limbah organik.

Berdasarkan data primer hasil analisis parameter nitrat, fosfat, COD, serta $\mathrm{pH}$ air irigasi didapatkan hasil yang berbeda-beda pada setiap inlet petak lahan. Saluran irigasi merupakan irigasi teknis yang tidak terdapat campuran dari sungai manapun. Namun, ada beberapa petak yang air irigasinya menggunakan air yang berasal dari petak sebelumnya sehingga kandungan unsurnya mempengaruhi petak selanjutnya. Kemudian warga seringkali membuang sampah pada jaringan irigasi teknis yang berpengaruh pada kualitas air irigasi.

\section{Indeks Kualitas Tanah}

Indeks kualitas tanah merupakan indeks yang dihitung berdasarkan pengukuran indikator kualitas tanah. Nilai dari kualitas tanah harus didasarkan pada seluruh parameter yang terpilih serta menunjukkan berlangsungnya seluruh fungsi tanah untuk masa sekarang serta masa yang akan datang. Hasil perhitungan Indeks Kualitas Tanah pada masing-masing satuan peta lahan (SPL) dan kriteria Kualitas Tanahnya dapat dilihat pada Tabel 3.

Kualitas tanah sawah di Kecamatan Bayat diketahui bahwa sampel tanah pada SPL 0 memiliki nilai IKT tertinggi yaitu 0,71 dengan kriteria baik. Sampel tanah pada SPL 1 memiliki nilai IKT sebesar 0,55 dengan kriteria sedang, sampel tanah pada SPL 2 memiliki nilai IKT 0,48 dengan kriteria sedang, dan sampel tanah pada SPL 3 memiliki nilai IKT 0,59 dengan kriteria sedang. Berdasarkan penilaian Indeks Kualitas Tanah (Tabel 4.), Satuan Peta Lahan 1 hingga Satuan Peta Lahan 3 yaitu lahan yang dialiri air irigasi Rawa Jombor memiliki Indeks Kualitas Tanah yang lebih rendah jika dibandingkan dengan Satuan Peta Lahan 0 yaitu lahan yang tidak dialiri irigasi Rawa Jombor. 
Tabel 3. Kriteria Indeks Kualitas Tanah Sawah Kecamatan Bayat

\begin{tabular}{ccccc}
\hline Satuan Peta Lahan (SPL) & Titik & IKT & Rata-Rata & Kriteria \\
\hline SPL 1 & TS 1 & 0.57 & & \\
Sawah irigasi, & TS 2 & 0.43 & 0,55 & Sedang \\
Litosol, 2,15 km & TS 3 & 0.65 & & \\
SPL 2 & TS 1 & 0,44 & & \\
Sawah irigasi, & TS 2 & 0,40 & 0,48 & Sedang \\
Alluvial, 3,25 km & TS 3 & 0,60 & & \\
SPL 3 & TS 1 & 0,56 & & Sedang \\
Sawah irigasi, & TS 2 & 0,53 & 0,59 & \\
Regosol, 4,49 km & TS 3 & 0,70 & & Baik \\
SPL 0 & TS 10 & 0,71 & 0,71 & \\
Sawah tadah hujan, Regosol & & & &
\end{tabular}

Keterangan: IKT = Indeks Kualitas Tanah

Nilai Indeks Kualitas Tanah pada fungsi melestarikan aktivitas biologi, pada SPL 1 hingga SPL 3 memiliki nilai yang lebih rendah jika dibandingkan dengan SPL 0. Hal ini dikarenakan pada indikator media perakaran SPL 1 hingga SPL 3 memiliki nilai yang rendah. Media perakaran memiliki tolok ukur atau parameter yaitu berat volume dan kedaaman akar. Pada parameter tersebut SPL 1 hingga SPL 3 memiliki nilai yang rendah, disebabkan karena sifat tanah yang disawahkan yaitu pengolahan dan penggenangan yang sengaja merusak agregat tanah sehingga memiliki struktur yang rusak, pori makro berkurang dan pori mikro bertambah. Hal ini menyebabkan berat volume menjadi sangat rendah. Pengolahan tanah sawah sepanjang tahun juga akan menyebabkan adanya lapisan tapak bajak di bawah lapisan olah tanah, yang menyebabkan perakaran menjadi pendek.

Pada indikator keharaan SPL 1 dan SPL 2 memiliki nilai yang lebih tinggi jika dibandingkan dengan SPL 3 dan SPL 0. Hal ini dikarenakan pada SPL 1 dan SPL 2 merupakan sawah yang intensitasnya lebih sering mendapatkan suplai air irigasi Rawa Jombor. Nilai keharaan yang tinggi dipengaruhi oleh suplai unsur hara yang berasal dari aliran irigasi teknis Rawa Jombor. Dilihat dari karakteristik air irigasi Rawa Jombor (Tabel 2.) memiliki kandungan fosfat yang lebih tinggi daripada kadar fosfat pada SPL 0 yaitu sawah tadah hujan yang tidak dialiri air Rawa Jombor.

Pada fungsi pengaturan dan penyaluran air SPL 1 hingga SPL 3 juga memiliki nilai yang lebih rendah jika dibandingkan dengan SPL 0. Hal ini juga disebabkan karena sifat tanah yang disawahkan yang menyebabkan parameter berat volume rendah dan porositas tidak optimal. Berat volume yang rendah akan menjadikan tanah lepas-lepas, sehingga porositas tidak optimal. Namun pada tanah sawah telah terdapat lapisan tapak bajak yang menyebabkan drainase tidak cepat walaupun keadaan pori total pada lapisan olah sangat tinggi. Keadaan ini disengaja pada pengolahan lahan sawah untuk mempertahankan kondisi air agar tetap tersedia bagi tanaman padi. Pada fungsi struktural penyangga SPL 1 hingga SPL 3 memiliki nilai yang lebih rendah dari SPL 0. Indikator untuk porositas tanah pada SPL 1 hingga SPL 3 rendah. Namun pada indikator proses mikrobiologi, SPL 1 memiliki nilai yang sangat tinggi jika dibandingkan SPL lainnya. Pada indikator ini digambarkan dengan parameter C-Organik dan N-Total tanah. Tingginya kadar C-Organik pada 
Tabel 4.Indeks Kualitas Tanah Sawah Kecamatan Bayat

\begin{tabular}{lcccc}
\hline \multirow{2}{*}{ Fungsi Tanah } & \multicolumn{4}{c}{ Satuan Peta Lahan } \\
\cline { 2 - 5 } & 1 & 2 & 3 & 0 \\
\hline Melestarikan aktivitas biologi & 0.20 & 0.18 & 0.18 & 0.24 \\
Media Perakaran & 0.01 & 0.02 & 0.05 & 0.11 \\
Kelengasan & 0.08 & 0.06 & 0.07 & 0.07 \\
Keharaan & 0.11 & 0.10 & 0.06 & 0.06 \\
\hline Pengaturan dan penyaluran air & 0.15 & 0.13 & 0.21 & 0.26 \\
Debu + lempung & 0.06 & 0.05 & 0.07 & 0.06 \\
Porositas & 0.08 & 0.08 & 0.10 & 0.12 \\
Berat volume & 0.01 & 0.01 & 0.04 & 0.08 \\
\hline Stuktural penyangga & 0.20 & 0.17 & 0.21 & 0.20 \\
Debu + lempung (\%) & 0.08 & 0.06 & 0.09 & 0.08 \\
Porositas (\%) & 0.06 & 0.06 & 0.08 & 0.09 \\
Proses Mikrobiologis & 0.18 & 0.04 & 0.02 & 0.02 \\
\hline Indeks Kualitas Tanah & 0.55 & 0.48 & 0.59 & 0.71 \\
\hline
\end{tabular}

SPL 1 dan 2 dikarenakan pada lahan ini dilakukan budidaya padi sepanjang tahun. Sehingga penambahan jerami pada petak sawah dapat menyebabkan meningkatnya kandungan bahan organik tanah.

Hasil Indeks Kualitas Tanah pada SPL 1 yaitu tanah sawah irigasi Rawa Jombor dengan jenis tanah Litosol memiliki nilai Indeks Kualitas Tanah sebesar 0,55 dengan kriteria sedang. SPL 1 memiliki jenis tanah Litosol yang memiliki ciri solum tanah yang tipis. Sehingga pada SPL 1 memiliki kedalaman akar paling rendah jika dibandingkan dengan SPL lainnya. Hasil Indeks Kualitas Tanah pada SPL 2 memiliki rata-rata sebesar 0,48 dengan kriteria kualitas tanah sedang. Dibandingkan dengan SPL lain, SPL 2 memiliki IKT paling rendah. SPL 2 merupakan lahan yang memiliki jenis tanah Alluvial. Tanah Alluvial merupakan tanah yang sering atau baru saja mengalami banjir. Karena terbentuk akibat banjir di musim hujan, maka sifat bahan-bahannya juga tergantung pada kekuatan banjir, asal serta macam bahan yang diangkut.

Tanah Alluvial Bayat merupakan tanah yang bersumber dari luapan banjir Kali Dengkeng ( BPS, 2010). SPL 2 memiliki kadar debu+lempung yang sangat tinggi sehingga berpengaruh pada fungsi tanah yaitu fungsi melestarikan aktivitas biologi, fungsi pengaturan dan penyaluran air serta fungsi struktural. Pada SPL ini ketiga fungsi tersebut memiliki nilai yang rendah, kadar berat volume rata-rata pada SPL 2 tergolong rendah dan porositas rata-rata juga memiliki nilai yang rendah.

Pada SPL 3 memiliki nilai yang paling tinggi diantara SPL yang dialiri air Rawa Jombor yaitu 0,59. Letak SPL 3 merupakan lahan yang jaraknya paling jauh dengan sumber irigasi memiliki kandungan debu+lempung yang optimal. Kadar debu+lempung pada kisaran angka 60\% memiliki nilai yang optimal untuk menjalankan fungsi tanah. Berbeda dengan SPL 1 dan SPL 2 yang memiliki kandungan debu+lempung cenderung tinggi. SPL 3 merupakan lahan yang memiliki jenis tanah Regosol, sehingga memiliki kadar debu+lempug yang lebih renah dibandingkan pada SPL 1 dan SPL2. SPL 3 memiliki rata-rata kadar P, dan K terendah dibanding SPL lainnya sehingga memiliki fungsi dalam melestarikan aktivitas mikroorganisme cenderung rendah. Akan tetapi pada SPL 3 ini memiliki 
nilai rata-rata porositas dan berat volume yang optimal sehingga meningkatkan indeks kualitas tanah dalam fungsi pengaturan dan penyaluran air serta struktural penyangga.

SPL 3 merupakan lahan yang intensitas terkena aliran irigasi lebih rendah dibandingkan dengan SPL 1 dan SPL 2. Pada musim kemarau panjang air Rawa Jombor sangat minim dan tidak mencukupi untuk sampai pada SPL 3, sehingga SPL 3 memiliki lahan yang jarang tergenang. Penggenangan dan pengolahan tanah sawah memang dianggap penting, tetapi pengolahan secara intensif dapat menyebabkan kerusakan tanah misalnya kerusakan struktur tanah, penurunan agregasi tanah, serta degradasi bahan organik (Alibasyah, 2001).

Pengolahan tanah padi sawah dapat menyebabkan perubahan permanen sifat morfologi dan sifat fisik dan kimia tanah asal. Perubahan-perubahan tersebut disebabkan oleh cara budidaya padi sawah, dan cara pembuatan sawah. Namun demikian perubahan tersebut kadang-kadang hanya sedikit terlihat dan umumnya hanya terbatas pada horion permukaan dan terkadang perubahan hanya bersifat sementara, dalam arti, terbatas hanya pada waktu sedang disawahkan. Sementara bila digunakan lagi untuk pertanian lahan kering (palawija), sifat tanah berubah kembali mendekati ke sifat tanah asalnya (Hardjowigeno et al., 2004).

Berbeda dengan SPL lainnya, SPL 0 merupakan satuan peta lahan yang tidak menggunakan air irigasi dari Rawa Jombor. Selain itu, SPL 0 merupakan sawah tadah hujan yang jarang ditanami padi atau dilakukan penyawahan. SPL 0 memiliki nilai IKT tertinggi yaitu 0,71 dengan kriteria baik. Pola tanam pada SPL 0 yaitu padi-padi-palawija atau padi-palawija-palawija tergantung dengan ketersediaan air hujan. Sehingga perubahan seperti tanah yang disawahkan tidak terlihat pada lokasi ini. Kandungan debu+lempung pada lokasi SPL 0 memiliki nilai terendah jika dibandingkan dengan SPL lain, namun masih dalam keadaan yang baik. Berat volume tanah pada lokasi ini memiliki nilai paling optimal sehingga tanah tidak terlalu lepas dan tidak terlalu mampat. Selain itu porositas pada lokasi ini memiliki nilai yang optimal yaitu 49,77\%. Porositas tanah yang mempunyai nilai kisaran 50\% memiliki ruang pori makro dan mikro yang seimbang, sehingga baik dalam melaksanakan ketiga fungsi tanah. Keadaan ini juga mempengaruhi kedalaman perakaran tanaman yang memiliki nilai tertinggi.

Air irigasi berpegaruh pada indikator keharaan, namun secara keseluruhan tidak mempengaruhi Indeks Kualitas Tanah pada lokasi penelitian. Sampel tanah yang dialiri air irigasi Rawa Jombor pada SPL 1, SPL 2, dan SPL 3 memiliki IKT yang lebih rendah dari SPL sawah tadah hujan, dipengaruhi oleh keadaan tanah yang disawahkan. SPL 1, SPL 2, dan SPL 3 memiliki IKT dengan kriteria sedang yang berarti kualitas tanah pada sampel tersebut masih mampu menunjang sasaran kualitas tanah yaitu produktivitas biologi baik itu tanaman ataupun hewan, lingkungan, dan kesehatan manusia. Dibuktikan dengan produktivitas padi pada lokasi dengan irigasi Rawa Jombor tergolong tinggi yaitu 6,29 ton/ha (BPP Bayat, 2018). Air irigasi yang berasal dari Rawa Jombor berpengaruh pada meningkatkan keharaan pada sawah yang dialirinya. Rawa Jombor merupakan waduk yang kualitas airnya dipengaruhi oleh aliran masuk air pada perairan dan juga pemanfatan waduk sebagai warung apung dan keramba jaring apung yang menyumbangkan limbah organik yang hasil dekomposisinya menyebabkan meningkatkan nutrient dalam perairan yang apabila melebihi baku mutu dapat menyebabkan eutrofikasi dan blooming algae. Karena frekuensi aktivitas manusia yang menyumbang limbah 
perairan Rawa jombor berbeda-beda setiap waktunya. Maka diperlukan pengujian karakteristik air secara berkala agar unsur hara yang dibawa melalui air irigasi dapat menguntungkan untuk sawah yang dialirinya.

\section{KESIMPULAN}

Kualitas air Rawa Jombor yang digunakan sebagai air irigasi sawah di Kecamatan Bayat Kabupaten Klaten berdasarkan parameter fosfat, nitrat, COD, dan $\mathrm{pH}$ air telah sesuai dengan baku mutu air irigasi dan memiliki kualitas yang baik dari setiap inlet satuan peta lahan sawah penelitian.Indeks Kualitas Tanah lahan sawah dengan irigasi Rawa Jombor di Kecamatan Bayat, Kabupaten Klaten pada Satuan Peta Lahan 1 sebesar 0,55 dengan kriteria kualitas tanah sedang, Satuan Peta Lahan 2 sebesar 0,48 dengan kriteria kualitas tanah sedang, Satuan Peta Lahan SPL 3 sebesar 0,59 dengan kriteria kualitas tanah sedang dan pada lokasi SPL 0 sebesar 0,71 dengan kriteria baik. Air irigasi berpengaruh pada Indeks Kualitas Tanah pada indikator keharaan, namun tidak mempengaruhi Indeks Kualitas Tanah secara keseluruhan.

\section{DAFTAR PUSTAKA}

Alibasyah, M. R. 2001. Efek Sistem Olah Tanah dan Mulsa Jagung Terhadap Stabilitas Agregat dan Kandungan C-organik pada Tanah Ultisol pada Musim Tanam Ketiga. Agrista Vol 5(1)

Ferril, I.J., Max, R. M, dan Niniek, W. 2014. Analisis Total Bakteri, Tom, Nitrat dan Fosfat di Perairan Rowo Jombor, Kabupaten Klaten. Diponegoro Journal of Maquares. Management of Aquatic Resources. Vol 3(4): 102-108

Hardjowigeno, S., H. Subagyo, dan M. Luthfi Rayes. 2004. Morfologi dan Klasifikasi Tanah Sawah

Kusumaningtyas. 2015. Kandungan Logam Berat Kadmium (Cd) pada Ikan Nila, Air, Sedimen Serta Kualitas Air di Rawa Jombor Klaten [Skripsi]. Universitas Sebelas Maret. Surakarta

Mausbach, MJ, dan CA. Seybold, 1998. Assessment of Soil Quality. Dalam: R. Lal (ed). Soil Quality and Agricultural Sustainability. Ann Arbor Press, Chelsea, Michigan

Partoyo. 2005. Analisis Indeks Kualitas Tanah Pertanian di Lahan Pasir Pantai Samas Yogyakarta. Jurnal Ilmu Pertanian Vol 12: 140-151

Plaster. 2003. Soil Science and Management. Dalam: Christine, P.D. 2009. Studi Kualitas Tanah pada Berbagai Sistem Penggunaan Lahan di Wilayah Desa Ngadipiro Kecamatan Nguntoronadi, Wonogiri [Skripsi]. Universitas Sebelas Maret. Surakarta 